\title{
Aminophylline modulates the permeability of endothelial cells via the Slit2-Robo4 pathway in lipopolysaccharide-induced inflammation
}

\author{
${\text { QIN } \mathrm{CHEN}^{1 *}, \text { XIAOMING ZHOU }}^{2 *}$, RUONAN HOU ${ }^{2}$, ZHILIANG ZHOU $^{3}$, \\ ZHIYI WANG ${ }^{2,4}$, YING $\mathrm{CHEN}^{2}, \mathrm{JIE} \mathrm{WENG}^{2}$ and JUNNAN XU ${ }^{3}$
}

\begin{abstract}
${ }^{1}$ Department of Intensive Care Unit, The First Affiliated Hospital of Wenzhou Medical University, Wenzhou, Zhejiang 325000; Departments of ${ }^{2}$ General Practice and ${ }^{3}$ Emergency Medicine, The Second Affiliated Hospital and

Yuying Children's Hospital of Wenzhou Medical University, Wenzhou, Zhejiang 325027;

${ }^{4}$ Center for Health Assessment, Wenzhou Medical University, Wenzhou, Zhejiang 325000, P.R. China
\end{abstract}

Received August 28, 2020; Accepted June 30, 2021

DOI: $10.3892 / \mathrm{etm} .2021 .10474$

\begin{abstract}
Sepsis and septic shock are the main cause of mortality in intensive care units. The prevention and treatment of sepsis remains a significant challenge worldwide. The endothelial cell barrier plays a critical role in the development of sepsis. Aminophylline, a non-selective phosphodiesterase inhibitor, has been demonstrated to reduce endothelial cell permeability. However, little is known regarding the role of aminophylline in regulating vascular permeability during sepsis, as well as the potential underlying mechanisms. In the present study, the Slit2/Robo4 signaling pathway, the downstream protein, vascular endothelial (VE)-cadherin and endothelial cell permeability were investigated in a lipopolysaccharide (LPS)-induced inflammation model. It was indicated that, in human umbilical vein endothelial cells (HUVECs), LPS downregulated Slit2, Robo4 and VE-cadherin protein expression levels and, as expected, increased endothelial cell permeability in vitro during inflammation. After administration of aminophylline, the protein expression levels of Slit2, Robo4 and VE-cadherin were upregulated and endothelial
\end{abstract}

Correspondence to: Dr Jie Weng, Department of General Practice, The Second Affiliated Hospital and Yuying Children's Hospital of Wenzhou Medical University, 109 Xueyuan Road, Wenzhou, Zhejiang 325027, P.R. China

E-mail: wengjie198811@163.com

Dr Junnan Xu, Department of Emergency Medicine, The Second Affiliated Hospital and Yuying Children's Hospital of Wenzhou Medical University, 109 Xueyuan Road, Wenzhou, Zhejiang 325027, P.R. China

E-mail: 459082056@qq.com

*Contributed equally

Key words: aminophylline, sepsis, Slit2-Robo4 pathway, VE-cadherin, HUVECs, endothelial cell permeability cell permeability was significantly improved. These results suggested that the permeability of endothelial cells could be mediated by VE-cadherin via the Slit2/Robo4 signaling pathway. Aminophylline reduced endothelial permeability in a LPS-induced inflammation model. Therefore, aminophylline may represent a promising candidate for modulating vascular permeability induced by inflammation or sepsis.

\section{Introduction}

Sepsis is a life-threatening organ dysfunction caused by dysregulated host response to infection $(1,2)$. Substantial efforts have been made to improve the outcome of patients with sepsis; however, treatment of sepsis remains a big challenge to clinicians (3). The underlying mechanism of its pathogenesis has not been fully elucidated (4,5). Recently, several studies have reported that the disruption of the endothelial cell barrier induced high vascular permeability, which serves a critical role in the development of sepsis (6-8).

In addition to regulating axon guidance and cell migration (9), the Slit/Robo signaling pathway (in which the Slit ligand binds to the Robo receptors) has also been demonstrated to serve an important role in the development of organs $(10,11)$. The Slit protein is a secretory extracellular matrix protein, which has three subtypes, Slit-1, -2 and -3 (12). With respect to the Robo protein, there are four subtypes, namely Robo-1, -2, -3 and -4 (12); the Robo-4 protein is specifically expressed in vascular endothelial (VE) cells and has been associated with the genesis and development of blood vessels, and serves an important role in maintaining the stability of VE cells (6). The Slit2/Robo4 signaling pathway was reported to be an endothelial permeability regulator, which effectively regulates VE permeability (13). The Slit2/Robo4 pathway alleviates the phagocytosis of VE-cadherin on the surface of VE cells mediated by cytokines; thus, stabilizing VE cells and maintaining the semi-permeable barrier of the microvessels (8). It is possible that the Slit2/Robo4 signaling pathway stabilizes the vasculature by enhancing VE-cadherin localization to the cell surface. The maintenance of the semi-permeable 
barrier between blood and peripheral tissues represents a key component of therapy for sepsis $(14,15)$.

Previous studies have shown that aminophylline, a non-selective phosphodiesterase inhibitor, reduces endothelial cell permeability (16-18). However, the underlying mechanisms remain unclear. In the present study, the mechanism of aminophylline in regulating the permeability of endothelial cells via the Slit2/Robo4 signaling pathway in a lipopolysaccharide (LPS)-induced inflammation model was investigated.

\section{Materials and methods}

Reagents and cells. The human umbilical vein endothelial cells (HUVECs) were purchased from the American Type Culture Collection. LPS (Escherichia coli O111:B4) and Slit2 ELISA kit (cat. no. HPA019511) were purchased from Sigma-Aldrich (Merck-KGaA), while aminophylline was purchased from Shandong Xinhua Pharmaceutical Co., Ltd. The Robo4 (cat. no. MAB50041), VE-cadherin (cat. no. AF1002), fibronectin (cat. no. AF1918) and integrin (cat. no. AF2045) primary antibodies were purchased from R\&D Systems, Inc. Alexa Fluor 488- (cat. no. sc-362257) and 594- (cat. no. sc-362277) conjugated and GAPDH antibodies (cat. no. sc-47724) were purchased from Santa Cruz Biotechnology, Inc. The N-terminal Slit2 (Slit2-N) protein was purchased from Abcam. FBS, trypsin, penicillin/streptomycin and DMEM were purchased from Thermo Fisher Scientific, Inc. All other chemicals were purchased from Sigma-Aldrich (Merck KGaA).

Cell culture. The HUVECs $\left(1 \times 10^{7}\right)$ were cultured in six-well culture plates with DMEM (supplemented with $10 \%$ FBS and $1 \%$ penicillin/streptomycin) and grown to $80 \%$ confluence. For all experiments, the cells were deprived of serum for $24 \mathrm{~h}$ before LPS was added. After culturing for $24 \mathrm{~h}$ with different concentrations of $\operatorname{LPS}\left(50,100\right.$ and $200 \mu \mathrm{g} / \mathrm{ml}\left(\right.$ at $\left.37^{\circ} \mathrm{C}\right)$, HUVECs were treated with aminophylline $(1 \mathrm{mM})$ for an additional $24 \mathrm{~h}\left(\right.$ at $\left.37^{\circ} \mathrm{C}\right)$. All experiments were repeated at least three times.

Immunofluorescence staining. The cells were fixed with $4 \%$ paraformaldehyde in PBS for $15 \mathrm{~min}$ at room temperature, then washed with PBS and blocked with $10 \%$ bovine serum in PBS for $1 \mathrm{~h}$ at room temperature. Subsequently, the cells were incubated overnight at $4^{\circ} \mathrm{C}$ with primary antibodies against Robo4 (dilution 1:100) and VE-cadherin (dilution 1:100). After washing with PBS adequately, the Alexa Fluor 488- or 594-conjugated secondary antibodies (dilution 1:200) were added and the samples were incubated at room temperature for $2 \mathrm{~h}$ in the dark. Subsequently, the cells were incubated with DAPI for nuclei staining at room temperature for $15 \mathrm{~min}$ ). Fluorescent images were captured using a fluorescent microscope (magnification, x400) (Nikon Corporation).

Western blot analysis. Western blot analysis was performed as previously described (19). Briefly, the protein concentrations were measured by BCA protein assay kit (Thermo Scientific, Inc.) according to the manufacturer's instructions. Equal amounts of total proteins (5-10 $\mu \mathrm{g})$ were subjected to $10 \%$ sodium dodecyl sulfate-polyacrylamide gel electrophoresis (SDS-PAGE) under reducing conditions and transferred to nitrocellulose membrane (EMD Millipore). After blocking with 5\% skimmed milk in TBS with $0.01 \%$ Tween-20 for $1 \mathrm{~h}$ at room temperature, the membranes were incubated with primary antibodies against Robo4 (dilution 1:1,000), VE-cadherin (dilution 1:1,000), fibronectin (dilution 1:1,000), integrin (dilution 1:1,000) and GAPDH (dilution 1:1,000) overnight at $4^{\circ} \mathrm{C}$, followed by treatment with the horseradish peroxidase (HRP)-conjugated secondary antibody for $1 \mathrm{~h}$ at room temperature. Finally, the protein expression level was detected with an enhanced chemiluminescence kit (Bio-Rad Laboratories, Inc.). The relative protein expression was analyzed by the software program Image J 1.42 (National Institutes of Health).

Reverse transcription-quantitative PCR (RT-qPCR). RT-qPCR was performed with SYBR Green PCR real-time PCR Master mix (Invitrogen; Thermo Fisher Scientific, Inc.), using real-time cycle conditions of $95^{\circ} \mathrm{C}$ and $5 \mathrm{~min}$, followed by 40 cycles of $95^{\circ} \mathrm{C}, 30 \mathrm{sec}$ and $60^{\circ} \mathrm{C}, 1 \mathrm{~min}$, as previously described (20). Data were analyzed through the comparative threshold cycle (CT) method. Briefly, RNA was extracted from the cells using TRIzol ${ }^{\circledR}$ (Invitrogen; Thermo Fisher Scientific, Inc.), according to the manufacturer's instructions. The total RNA concentration and purity were assessed using UV spectrophotometry (20). cDNA was synthesized from total RNA using RT and the Superscript III First Strand RT-PCR kit (Invitrogen; Thermo Fisher Scientific, Inc.), according to the manufacturer's instructions $(19,20)$. The primers used in the PCR were as follows: Slit2: CCGAAGGTTACAGTG GCTTGTTCT (Forward), CCGCTGTCTTCATCTGTG GCAAT (Reverse); GAPDH: GATGCTGGTGCTGAGTAT GRCG (Forward), GTGGTGCAGGATGCATTGCTCTGA (Reverse). The PCR products were amplified and identified using 2\% agarose gel electrophoresis. GAPDH served as an internal control. The gene products were expressed as a change in mRNA expression levels relative to GAPDH.

Transendothelial permeability assay. The HUVECs were cultured in Transwell upper chambers $(8-\mu \mathrm{m}$ pore size, Corning, Inc.) at $37^{\circ} \mathrm{C}$ in a humidified incubator with $5 \% \mathrm{CO}_{2}$ and maintained until confluent. After $24 \mathrm{~h}$ of culture with LPS, the HUVECs were treated with aminophylline for an additional $24 \mathrm{~h}$ at $37^{\circ} \mathrm{C}$. Then, complete medium containing $1 \mathrm{mg} / \mathrm{ml}$ FITC-conjugated dextran or $0.5 \mu \mathrm{M}$ HRP replaced the medium in the upper Transwell chamber (incubation was $6 \mathrm{~h}$ and $37^{\circ} \mathrm{C}$ ) The fluorescence in the lower chamber was measured using a TECAN GeNios microplate reader (Tecan Group, Ltd.). The HRP was removed from the lower chamber and analyzed spectrophotometrically at $492 \mathrm{~nm}$ with buffer containing $0.5 \mathrm{mM}$ tetramethylbenzidine. For normalization, FITC-conjugated dextran and HRP concentration was calculated and divided by the concentration of FITC-conjugated dextran and HRP at baseline with no LPS added.

Statistical analysis. All the experimental data are presented as the mean \pm standard error of the mean and were analyzed using a Student's t-test or one-way ANOVA followed by a Tukey's multiple comparisons test. Statistical analyses were performed using the SPSS v19.0. software (IBM Corp.). 

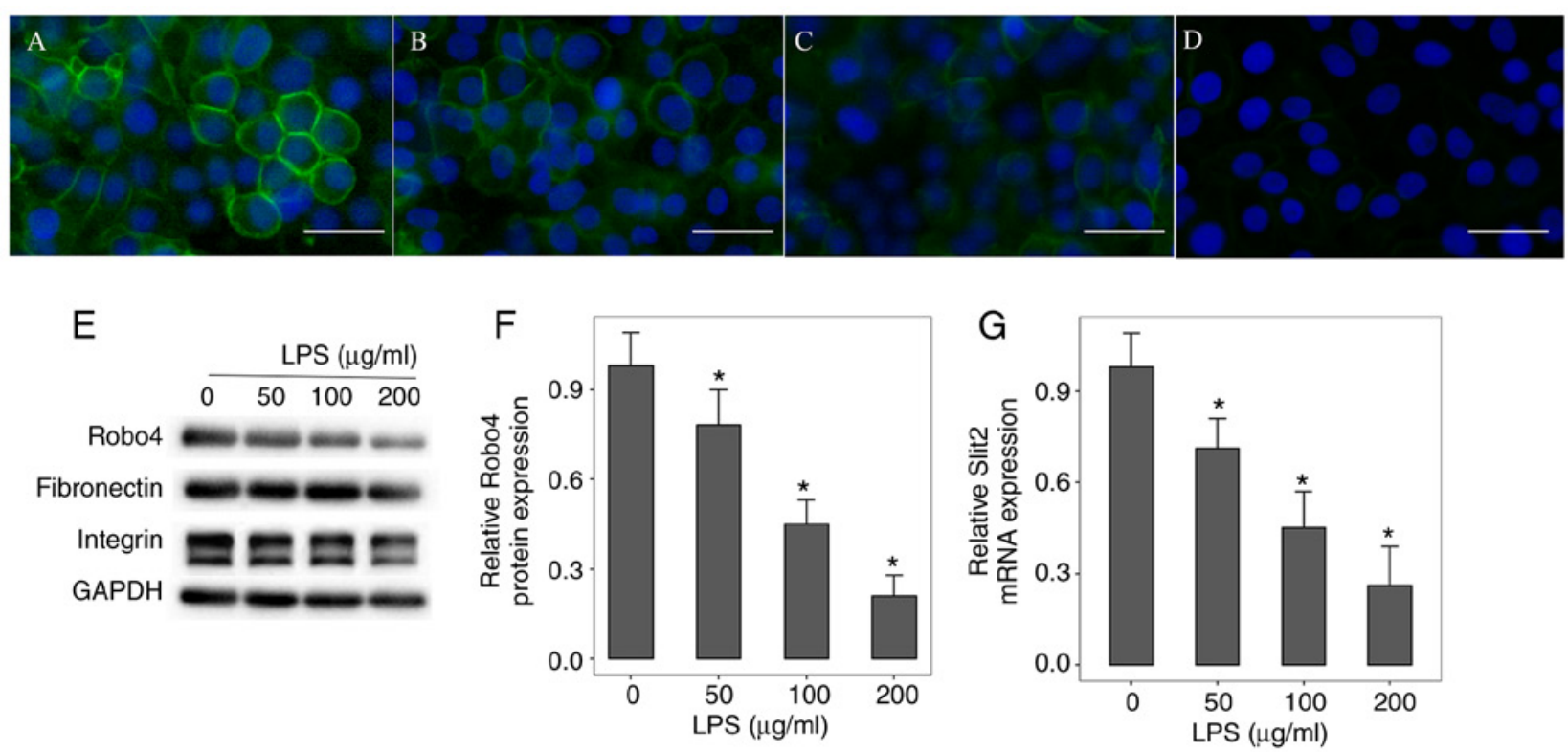

Figure 1. Expression of Slit2 and Robo4 in LPS-induced inflammation. HUVECs were incubated with (A) 0, (B) 50, (C) $100 \mathrm{or}$ (D) $200 \mu \mathrm{g} / \mathrm{ml} \mathrm{LPS} \mathrm{for} 24 \mathrm{~h}$. Immunofluorescent staining revealed that Robo4 protein expression level was decreased in a dose-dependent manner. Scale bar, $50 \mu \mathrm{m}$. Original magnification, $x$ 400. Green indicates Robo4, while blue indicates DAPI. (E and F) Western blot analysis of Robo4, fibronectin and integrin protein expression level. (G) Reverse transcription-quantitative PCR analysis of Slit 2 mRNA expression levels. " $\mathrm{P}<0.05$ vs. control group. The data are presented as the mean \pm standard error of the mean. All experiments were repeated at least three times. LPS, lipopolysaccharide; DAPI, 4',6-diamidino-2 phenylindole; HUVECs, human umbilical vein endothelial cells.

$\mathrm{P}<0.05$ was considered to indicate a statistically significant difference.

\section{Results}

Expression level of Slit2 and Robo4 in LPS-induced inflammation. Firstly, the mRNA and protein expression level of Slit2 and Robo4, respectively, in the HUVECs following LPS-induced inflammation was investigated. Immunofluorescent staining and western blot analysis revealed that the Robo4 protein expression level was decreased following LPS-induced inflammation in a dose-dependent manner (Fig. 1A-F). In addition, the expression levels of other cell surface markers, such as fibronectin and integrin, did not change under LPS stimulation (Fig. 1E). RT-qPCR analysis revealed that the Slit 2 mRNA expression level was significantly downregulated in HUVECs after LPS stimulation (Fig. 1G).

Integrity and stability of HUVECs in LPS-induced inflammation. Subsequently, the VE-cadherin protein expression level and permeability of HUVECs following LPS-induced inflammation was investigated. Immunofluorescent staining and western blot analysis revealed that VE-cadherin protein expression level was significantly downregulated compared with the Robo4 protein expression level (Fig. 2A-F). The Transwell permeability assay revealed that LPS significantly increased HUVECs permeability in a dose-dependent manner (Fig. 2G and $\mathrm{H}$ ).

Slit2/Robo4 pathway modulates VE-cadherin protein expression level in LPS-induced inflammation. Based on the aforementioned results, the association between the Slit2/Robo4 signaling pathway and the VE-cadherin protein expression level in LPS-induced inflammation was investigated. The HUVECs stimulated by LPS were incubated with $20 \mathrm{ng} / \mathrm{ml}$ Slit2-N for $24 \mathrm{~h}$. Western blot analysis showed that the protein expression level of VE-cadherin was significantly upregulated (Fig. 3A and B). When the Robo4 receptor inhibitor, RoboN was added, the VE-cadherin protein expression level did not significantly change following LPS-induced inflammation (Fig. 3A and C).

Aminophylline represses endothelial permeability by upregulating VE-cadherin protein expression levels via the Slit2/Robo4 signaling pathway. Next, the effect of aminophylline in LPS-induced inflammation was investigated. To explore the effect of aminophylline on endothelial cells permeability, three different aminophylline concentrations (10 and $100 \mu \mathrm{m}$ and $1 \mathrm{mM}$ ) were tested. It was revealed that the $1 \mathrm{mM}$ aminophylline significantly reduced the permeability of endothelial cells (Fig. S1), so $1 \mathrm{mM}$ aminophylline was used for subsequent experiments in the current study. It was demonstrated that aminophylline upregulated Robo4 and VE-cadherin protein expression levels in HUVECs using immunofluorescent staining (Fig. 4A-H) and western blot analysis (Fig. 5A-C). RT-qPCR revealed that Slit2 mRNA expression level was also upregulated in HUVECs following aminophylline treatment (Fig. 5D). In addition, the Transwell permeability assay revealed that aminophylline at $200 \mu \mathrm{g} / \mathrm{ml}$ significantly alleviated endothelial cell permeability in LPS-induced inflammation (Fig. 5E).

\section{Discussion}

The pathophysiological process of LPS-induced inflammation is similar in nature to acute inflammation or sepsis (21). The 

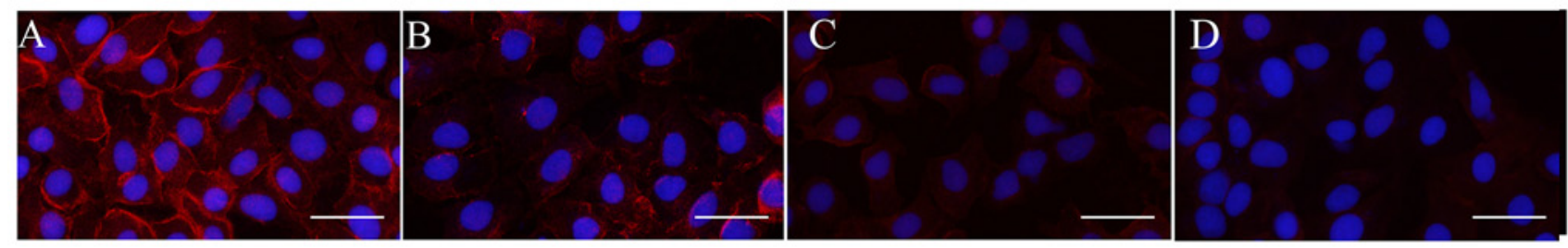

$\mathrm{E}$

$\mathrm{F}$

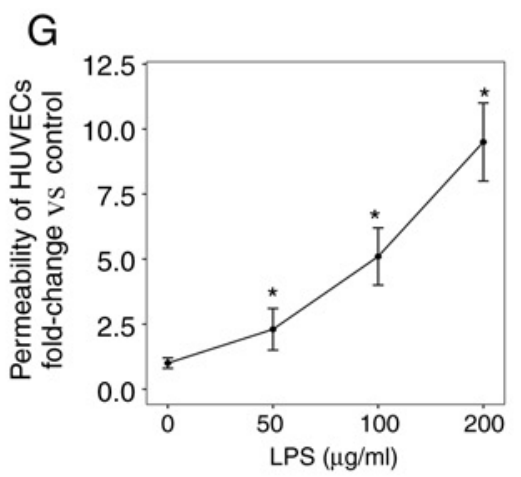

$\mathrm{H}$
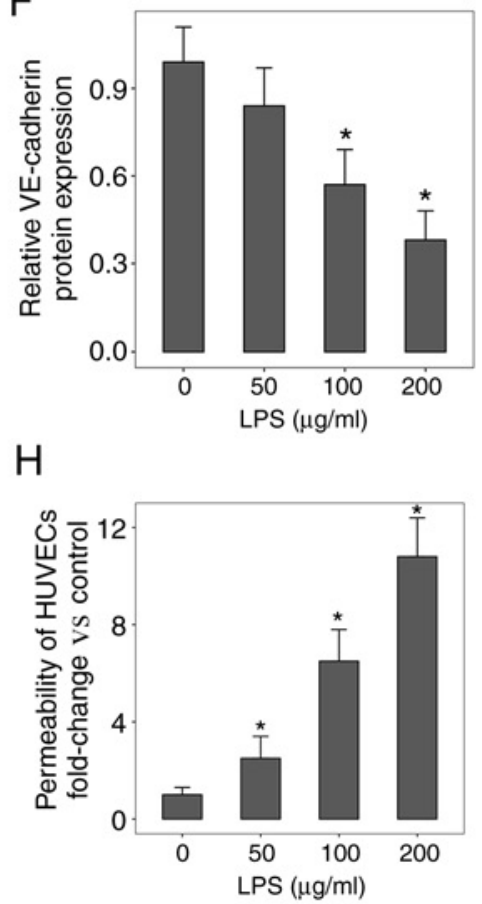

Figure 2. VE-cadherin expression level and permeability of HUVECs in LPS-induced inflammation. HUVECs were incubated with (A) 0, (B) 50, (C) 100 and (D) $200 \mu \mathrm{g} / \mathrm{ml}$ LPS for $24 \mathrm{~h}$. Immunofluorescent staining demonstrated that VE-cadherin protein expression level was decreased in a dose-dependent manner. Scale bar, $50 \mu \mathrm{m}$. Original magnification, $\mathrm{x}$ 400. Red indicates VE-cadherin and blue indicates DAPI. (E and F) Western blot analysis of VE-cadherin protein expression level. (G) Dextran permeability assay and (H) HRP permeability assay showed that LPS significantly increased permeability in a dose-dependent manner. ${ }^{*} \mathrm{P}<0.05$ vs. control group. The data are presented as the mean \pm standard error of the mean. All experiments were repeated at least three times. VE, vascular endothelial; HUVECs, human umbilical vein endothelial cells; LPS, lipopolysaccharide.

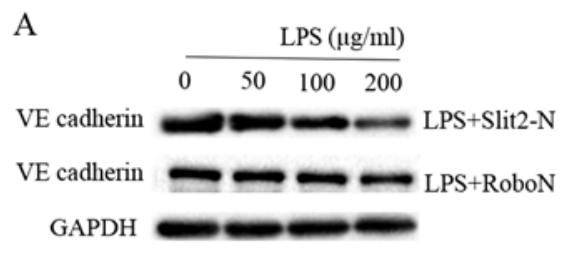

A
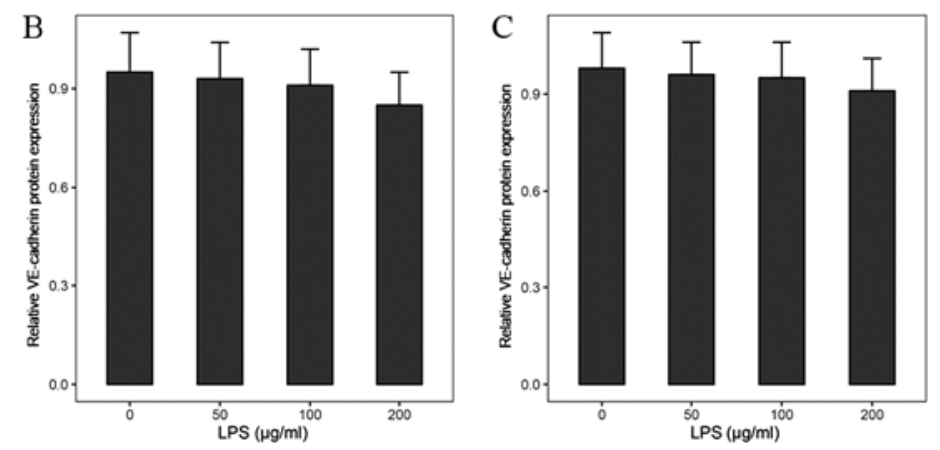

Figure 3. A Slit2/Robo4 signaling pathway modulates VE-cadherin protein expression level in LPS-induced Inflammation. (A and B) HUVECs were incubated with LPS $(50,100$ and $200 \mu \mathrm{g} / \mathrm{ml})$ for $24 \mathrm{~h}$ and treated with $20 \mathrm{ng} / \mathrm{ml}$ Slit2-N for $12 \mathrm{~h}$, then the protein expression level of VE-cadherin was analyzed using western blot analysis. (A and C) The Robo4 receptor inhibitor, RoboN was added before LPS stimulation, then the VE-cadherin protein expression level was examined using western blot analysis. VE, vascular endothelial; HUVECs, human umbilical vein endothelial cells; LPS, lipopolysaccharide.

endothelial receptor, Robo4 serves critical roles in endothelial cells, and the Slit2/Robo4 signaling pathway is responsible for regulating the expression level of the cell tight junction protein, VE-cadherin and endothelial permeability $(22,23)$. In the present study was revealed that LPS treatment decreased VE-cadherin protein expression levels and increased endothelial permeability in vitro by downregulating the Slit2/Robo4 signaling pathway. Aminophylline alleviated LPS-induced endothelial cell permeability, and upregulated Slit2, Robo4 and VE-cadherin protein expression levels.

Robo4 is a membrane protein, located on the surface of VE cells, and acts as a receptor for Slit2, which serves an important 

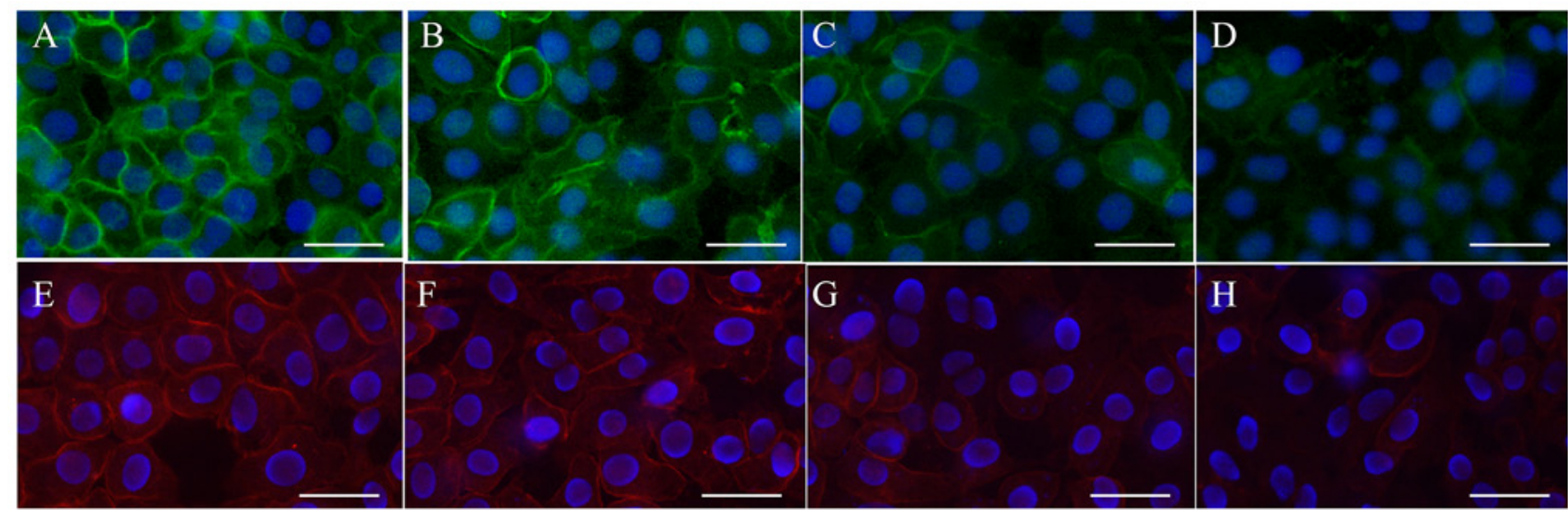

$\mathrm{H}$

Figure 4. Robo4 and VE-cadherin protein expression levels following aminophylline treatment. The HUVECs were incubated with (A and E) $0 \mu \mathrm{g} / \mathrm{ml} \mathrm{LPS}$, (B and F) $50 \mu \mathrm{g} / \mathrm{ml} \mathrm{LPS} \mathrm{+} \mathrm{aminophylline,} \mathrm{(C} \mathrm{and} \mathrm{G)} 100 \mu \mathrm{g} / \mathrm{ml} \mathrm{LPS} \mathrm{+} \mathrm{aminophylline} \mathrm{and} \mathrm{(D} \mathrm{and} \mathrm{H)} 200 \mu \mathrm{g} / \mathrm{ml}+$ aminophylline, both for $24 \mathrm{~h}$, sequentially. Immunofluorescent staining demonstrated that Robo4 and VE-cadherin protein expression level were both upregulated following aminophylline treatment. Scale bar, $50 \mu \mathrm{m}$. Original magnification, x400. Green indicates Robo4, red indicates VE-cadherin and blue indicates DAPI. VE, vascular endothelial; HUVECs, human umbilical vein endothelial cells; LPS, lipopolysaccharide; DAPI, 4',6-diamidino-2 phenylindole.

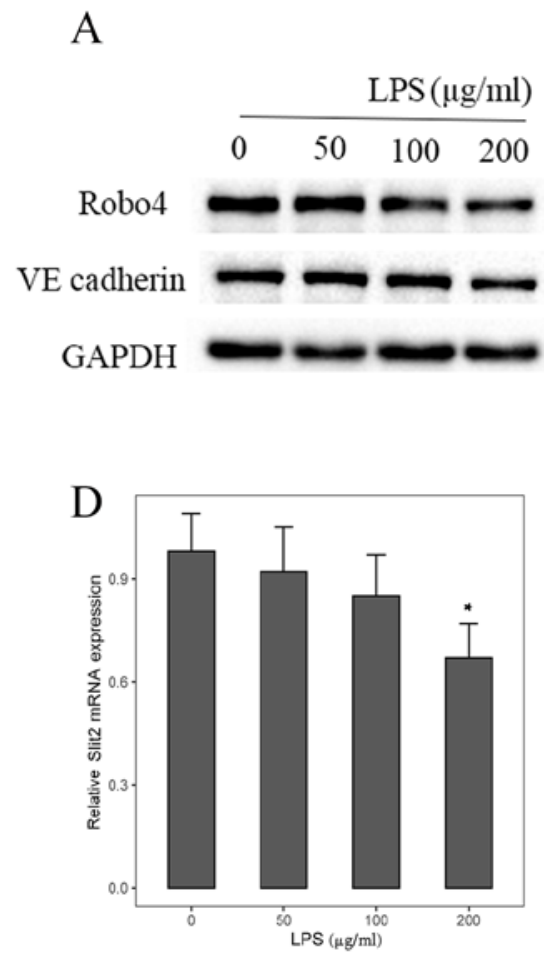

B

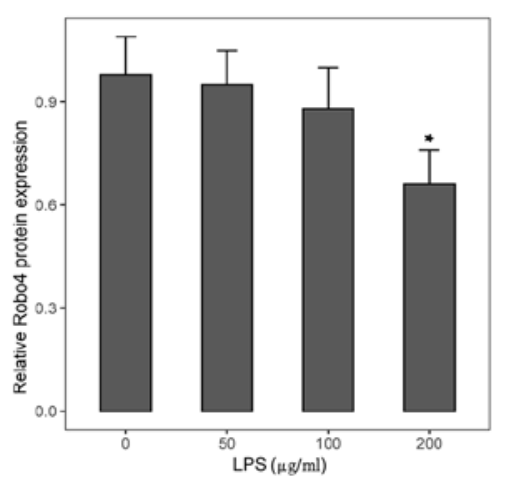

E

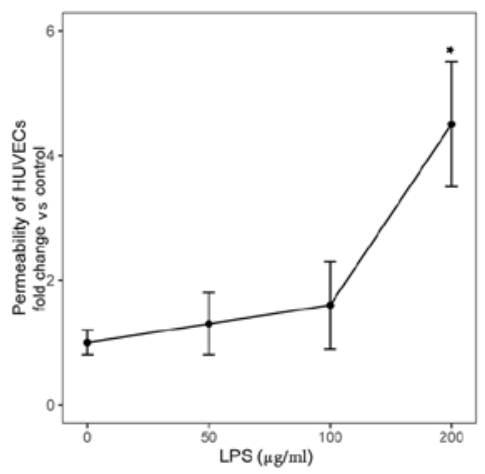

C

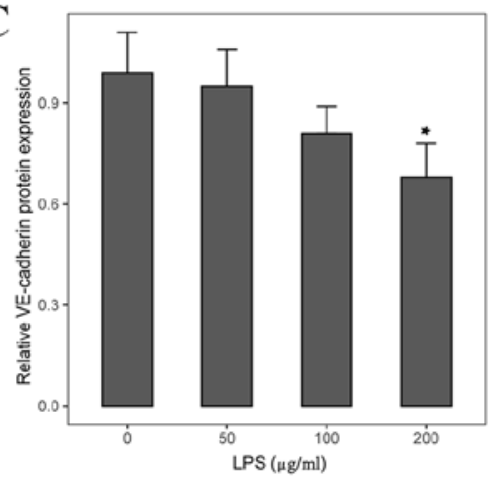

Figure 5. Aminophylline represses endothelial permeability by upregulating VE-cadherin protein expression level via the Slit2/Robo4 signaling pathway. The HUVECs were incubated with LPS $(50,100$ and $200 \mu \mathrm{g} / \mathrm{ml})$ for $24 \mathrm{~h}$, followed by treatment with 1 mM aminophylline for an additional $24 \mathrm{~h}$. Western blot analysis of (A and B) Robo4 and (A and C) VE-cadherin protein expression level. The Robo4 and VE-cadherin protein expression level significantly increased following aminophylline treatment. (D) Reverse transcription-quantitative PCR analysis of Slit2 mRNA expression level. (E) HUVECs permeability assay showed that aminophylline significantly reduced the permeability following aminophylline treatment. ${ }^{*} \mathrm{P}<0.05$ vs. control group. The data are presented as the mean \pm standard error of the mean. All the experiments were repeated at least three times. VE, vascular endothelial; HUVECs, human umbilical vein endothelial cells; LPS, lipopolysaccharide.

role in stabilizing the vascular endothelium. Zhang et al (24) found that targeting the Slit2/Robo4 signaling pathway may protect the integrity of the lymphatic barrier and reduce lymphatic endothelial hyperpermeability. Shirakura et al (25) reported that Robo4 suppressed vascular hyperpermeability and improved the survival of Robo $4^{-/-}$mice in a mouse model of inflammation. Robo4 was also responsible for stabilizing the VE-cadherin protein at endothelial cell junctions, in an inflammation-induced hyperpermeability model (25). A transfusion-related acute lung injury study indicated that the Slit2/Robo4 signaling pathway modulates endothelial cell permeability, and regulates VE-cadherin protein expression level to maintain endothelial barrier function (23). Similar results were also obtained in the present study with an LPS-induced inflammation cell line model. Nevertheless, another study revealed that Robo4 acted as a ligand to bind 
UNC5B (a vascular Netrin receptor), and not to Slit2, which may inhibit VEGF-induced vascular hyperpermeability (26).

Endothelial barrier dysfunction and capillary leakage contribute to the pathological process of organ failure in sepsis and in sepsis-related complications (27). It is well-known that cell-cell junctions (primarily composed of VE-cadherin) are an important component of the vascular barrier (28). Therapeutic strategies targeting capillary leakage and endothelial cell dysfunction have been considered to be potentially effective in improving the clinical outcome of patients with sepsis (5).

Aminophylline acts as a non-selective phosphodiesterase inhibitor, and has been demonstrated to have effects on multiple systems, such as the pulmonary (29-31), renal (32-34) and cardiovascular systems (35). A total of 30 years ago, Harada et al (36) demonstrated that aminophylline attenuated the multiple organ albumin leaks in septic guinea pigs. Previous studies, focusing on animal models of inflammatory cytokine-induced acute lung injury, reported that pulmonary vascular permeability was reduced following aminophylline administration. These protective effects may be due to elevation of intracellular cAMP/cGMP and/or inhibition of tumor necrosis, in which pulmonary vascular endothelium leakage and pulmonary edema are alleviated (37-40). Notably, the results in the present study are slightly different from previous studies. To the best of our knowledge, this is the first study that demonstrated that aminophylline upregulated the protein expression level of Slit2, Robo4 and VE-cadherin, and decreased endothelial cell permeability, in HUVECs in a LPS-induced inflammation model. The results from the present study suggest that the protection of endothelial integrity and stability by aminophylline may be mediated by VE-cadherin, which was modulated via the Slit2/Robo4 signaling pathway. The maintenance of the endothelial barrier function is a critical treatment strategy for sepsis $(6,13,15)$. In addition, the results from the present study also indicated that aminophylline might be a promising candidate for sepsis therapy, as well as other vascular hyperpermeability diseases. However, prospective studies are required to confirm the results of the present study.

In conclusion, the present study revealed that LPS downregulates the Slit2, Robo4 and VE-cadherin protein expression levels during endotoxemia. The permeability of endothelial cells was mediated by VE-cadherin via the Slit2/Robo4 signaling pathway. Aminophylline reduced endothelial cell permeability during LPS-induced inflammation. Taken together, aminophylline may represent a promising candidate for modulating vascular permeability induced by endotoxemia or sepsis.

\section{Acknowledgements}

Not applicable.

\section{Funding}

The present study was supported by the National Natural Science Foundation of China (grant. no. 81772054), Zhejiang Medicines Health Science and Technology Program (grant. no. 2016KYB189) and the Wenzhou Science and Technology Bureau (grant. nos. Y20170179 and Y20160114).

\section{Availability of data and materials}

The datasets used and/or analyzed during the current study are available from the corresponding author on reasonable request.

\section{Authors' contributions}

JX, JW, QC and XZ designed the study and performed the experiments. $\mathrm{RH}$ and $\mathrm{ZZ}$ collected the data. $\mathrm{ZW}$ and $\mathrm{YC}$ analyzed the data. QC and XZ prepared the manuscript. QC and JX confirm the authenticity of all the raw data. All authors read and approved the final manuscript.

\section{Ethics approval and consent to participate}

Not applicable.

\section{Patient consent for publication}

Not applicable.

\section{Competing interests}

The authors declare that they have no competing interests.

\section{References}

1. Shankar-Hari M, Phillips GS, Levy ML, Seymour CW, Liu VX, Deutschman CS, Angus DC, Rubenfeld GD and Singer M: Sepsis Definitions Task Force: Developing a new definition and assessing new clinical criteria for septic shock: For the third international consensus definitions for sepsis and septic shock (Sepsis-3). JAMA 315: 775-787, 2016.

2. Weng J, Wu H, Xu Z, Xi H, Chen C, Chen D, Gong Y, Hua Y and Wang $\mathrm{Z}$ : The role of propionic acid at diagnosis predicts mortality in patients with septic shock. J Crit Care 43: 95-101, 2018.

3. Cecconi M, Evans L, Levy M and Rhodes A: Sepsis and septic shock. Lancet 392: 75-87, 2018.

4. Lelubre $\mathrm{C}$ and Vincent JL: Mechanisms and treatment of organ failure in sepsis. Nat Rev Nephrol 14: 417-427, 2018.

5. Cross D, Drury R, Hill J and Pollard AJ: Epigenetics in sepsis: Understanding its role in endothelial dysfunction, immunosuppression, and potential therapeutics. Front Immunol 10: 1363, 2019.

6. Ni J, Lin M, Jin Y, Li J, Guo Y, Zhou J, Hong G, Zhao G and $\mathrm{Lu} \mathrm{Z:} \mathrm{Gas6}$ attenuates sepsis-induced tight junction injury and vascular endothelial hyperpermeability via the $\mathrm{Axl} / \mathrm{NF}-\kappa \mathrm{B}$ signaling pathway. Front Pharmacol 10: 662, 2019.

7. Gao S, Wake H, Gao Y, Wang D, Mori S, Liu K, Teshigawara K, Takahashi $\mathrm{H}$ and Nishibori M: Histidine-rich glycoprotein ameliorates endothelial barrier dysfunction through regulation of NF- $\kappa \mathrm{B}$ and MAPK signal pathway. Br J Pharmacol 176: 2808-2824, 2019.

8. Martinez-Quinones P, Komic A, McCarthy CG, Webb RC and Wenceslau CF: Targeting endothelial barrier dysfunction caused by circulating bacterial and mitochondrial $\mathrm{N}$-formyl peptides with deformylase. Front Immunol 10: 1270, 2019.

9. Rothberg JM, Hartley DA, Walther Z and Artavanis-Tsakonas S: Slit: An EGF-homologous locus of D. Melanogaster involved in the development of the embryonic central nervous system. Cell 55: 1047-1059, 1988.

10. Mommersteeg MT, Andrews WD, Ypsilanti AR, Zelina P, Yeh ML, Norden J, Kispert A, Chedotal A, Christoffels VM and Parnavelas JG: Slit-roundabout signaling regulates the development of the cardiac systemic venous return and pericardium. Circ Res 112: 465-475, 2013.

11. Fan X, Li Q, Pisarek-Horowitz A, Rasouly HM, Wang X, Bonegio RG, Wang H, McLaughlin M, Mangos S, Kalluri R, et al: Inhibitory effects of Robo2 on nephrin: A crosstalk between positive and negative signals regulating podocyte structure. Cell Rep 2: 52-61, 2012. 
12. Jiang Z, Liang G, Xiao Y, Qin T, Chen X, Wu E, Ma Q and Wang Z: Targeting the SLIT/ROBO pathway in tumor progression: Molecular mechanisms and therapeutic perspectives. Ther Adv Med Oncol 11: 1758835919855238, 2019.

13. Zhao H, Anand AR and Ganju RK: Slit2-Robo4 pathway modulates lipopolysaccharide-induced endothelial inflammation and its expression is dysregulated during endotoxemia. J Immunol 192: 385-393, 2014.

14. Schnoor M, Ponce AG, Vadillo E, Pelayo R, Rossaint $\mathrm{J}$ and Zarbock A: Actin dynamics in the regulation of endothelial barrier functions and neutrophil recruitment during endotoxemia and sepsis. Cell Mol Life Sci 74: 1985-1997, 2017.

15. Xiao F, Wang D, Kong L, Li M, Feng Z, Shuai B, Wang L, Wei Y, Li H, Wu S, et al: Intermedin protects against sepsis by concurrently re-establishing the endothelial barrier and alleviating inflammatory responses. Nat Commun 9: 2644, 2018.

16. Möller AD and Grände PO: Low-dose prostacyclin is superior to terbutaline and aminophylline in reducing capillary permeability in cat skeletal muscle in vivo. Crit Care Med 27: 130-136, 1999.

17. Korn C, Neidlein R, Strein K and Wilhelms OH: Comparison of the effects of ularitide acetate and other bronchorelaxing substances on the thrombin-induced permeability raise of human endothelial cell monolayers. Arzneimittelforschung 48: 251-258, 1998.

18. Foy T, Marion J, Brigham KL and Harris TR: Isoproterenol and aminophylline reduce lung capillary filtration during high permeability. J Appl Physiol Respir Environ Exerc Physiol 46: 146-151, 1979

19. Weng J, Tu M, Wang P, Zhou X, Wang C, Wan X, Zhou Z, Wang L, Zheng X, Li J, et al: Amiodarone induces cell proliferation and myofibroblast differentiation via ERK1/2 and p38 MAPK signaling in fibroblasts. Biomed Pharmacother 115: 108889, 2019.

20. Weng J, Chen H, Wu H, Tu M, Wang Z, Chen D, Wang Z and Chen C: Amiodarone induces epithelial-mesenchymal transition in A549 cells via activation of TGF- $\beta 1$. Drug Chem Toxicol 43: 415-422, 2020

21. Dickson K and Lehmann C: Inflammatory response to different toxins in experimental sepsis models. Int J Mol Sci 20: 4341, 2019.

22. Zhang F, Prahst C, Mathivet T, Pibouin-Fragner L, Zhang J, Genet G, Tong R, Dubrac A and Eichmann A: The Robo4 cytoplasmic domain is dispensable for vascular permeability and neovascularization. Nat Commun 7: 13517, 2016

23. Weng J, Zhou X, Xie H, Gao Y, Wang Z and Gong Y: Slit2/Robo4 signaling pathway modulates endothelial hyper-permeability in a two-event in vitro model of transfusion-related acute lung injury. Blood Cells Mol Dis 76: 7-12, 2019.

24. Zhang X, Yu J, Kuzontkoski PM, Zhu W, Li DY and Groopman JE: Slit2/Robo4 signaling modulates HIV-1 gp120-induced lymphatic hyperpermeability. PLoS Pathog 8: e1002461, 2012.

25. Shirakura K, Ishiba R, Kashio T, Funatsu R, Tanaka T, Fukada SI Ishimoto K, Hino N, Kondoh M, Ago Y, et al: The Robo4-TRAF7 complex suppresses endothelial hyperpermeability in inflammation. J Cell Sci 132: jes220228, 2019.

26. Koch AW, Mathivet T, Larrivée B, Tong RK, Kowalski J, Pibouin-Fragner L, Bouvrée K, Stawicki S, Nicholes K, Rathore N, et al: Robo4 maintains vessel integrity and inhibits angiogenesis by interacting with UNC5B. Dev Cell 20: 33-46, 2011.
27. Goldenberg NM, Steinberg BE, Slutsky AS and Lee WL: Broken barriers: A new take on sepsis pathogenesis. Sci Transl Med 3: 88 ps25, 2011.

28. Darwish I and Liles WC: Emerging therapeutic strategies to prevent infection-related microvascular endothelial activation and dysfunction. Virulence 4: 572-582, 2013.

29. Mizus I, Summer W, Farrukh I, Michael JR and Gurtner GH: Isoproterenol or aminophylline attenuate pulmonary edema after acid lung injury. Am Rev Respir Dis 131: 256-259, 1985.

30. Lindenschmidt RC and Witschi H: Attenuation of pulmonary fibrosis in mice by aminophylline. Biochem Pharmacol 34: 4269-4273, 1985

31. Nowak D, Rozniecki J, Ruta U, Bednarowicz A and Izdebski J: The influence of aminophylline on human neutrophils-possible protection of lung from proteolytic injury. Arch Immunol Ther Exp (Warsz) 36: 351-360, 1988.

32. Bhatt GC, Gogia P, Bitzan M and Das RR: Theophylline and aminophylline for prevention of acute kidney injury in neonates and children: A systematic review. Arch Dis Child 104: 670-679, 2019.

33. Seo K, Choi JW, Kim DW, Han D, Noh SJ and Jung HS: Aminophylline effect on renal ischemia-reperfusion injury in mice. Transplant Proc 49: 358-365, 2017.

34. Su X, Xie X, Liu L, Lv J, Song F, Perkovic V and Zhang H Comparative effectiveness of 12 treatment strategies for preventing contrast-induced acute kidney injury: A systematic review and bayesian network meta-analysis. Am J Kidney Dis 69: 69-77, 2017.

35. Matthay RA and Mahler DA: Theophylline improves global cardiac function and reduces dyspnea in chronic obstructive lung disease. J Allergy Clin Immunol 78 (4 Pt 2): 793-799, 1986.

36. Harada H, Ishizaka A, Yonemaru M, Mallick AA, Hatherill JR, Zheng H, Lilly CM, O'Hanley PT and Raffin TA: The effects of aminophylline and pentoxifylline on multiple organ damage after escherichia coli sepsis. Am Rev Respir Dis 140: 974-980, 1989.

37. Hsu K, Wang D, Chang ML, Wu CP and Chen HI: Pulmonary edema induced by phorbol myristate acetate is attenuated by compounds that increase intracellular cAMP. Res Exp Med (Berl) 196: 17-28, 1996.

38. Sciuto AM, Strickland PT, Kennedy TP and Gurtner GH: Postexposure treatment with aminophylline protects against phosgene-induced acute lung injury. Exp Lung Res 23: 317-332, 1997.

39. Berthiaume Y: Effect of exogenous cAMP and aminophylline on alveolar and lung liquid clearance in anesthetized sheep. J Appl Physiol (1985) 70: 2490-2497, 1991.

40. Sato K, Stelzner TJ, O'Brien RF, Weil JV and Welsh CH: Pentoxifylline lessens the endotoxin-induced increase in albumin clearance across pulmonary artery endothelial monolayers with and without neutrophils. Am J Respir Cell Mol Biol 4: 219-227, 1991.

This work is licensed under a Creative Commons Attribution-NonCommercial-NoDerivatives 4.0 International (CC BY-NC-ND 4.0) License. 